\title{
Theoretical Model of the Tropospheric Pressure Variation on the Height
}

\author{
Raul C. Perez \\ LIHANDO. CEDS, Dpto de Materias Básicas, Facultad Regional Mendoza, Universidad Tecnológica Nacional, Rodriguez 276, \\ Mendoza 5570, Argentina
}

\begin{abstract}
In the study and the research of the troposphere, the knowledge about its pressure variation on the height is necessary and important. Of course, exist the sounding to make this work, but not always it is possible to access to sounding data when is necessary, so then, it is important to has others alternatives methods in order to replace it. The troposphere is basically a fluid, susceptible to be studied under the fluid mechanics and thermodynamics of the ideals gases without loss generalities. So, it is possible to study of the atmospheric air like as a continuous perfect gas. These facts are important questions to study the troposphere under the laws and beginning Physics, using its respective equations, in order to get a theoretical model to simulate the behavior of its thermodynamics variables and parameters. Working on this line, it was developed a model in order to simulate the tropospheric pressure variation on the height from its measure on surface data.
\end{abstract}

Key words: Atmospherics pressure, tropospheric pressure.

\section{Introduction}

It is possible to study a $V$ volume to atmospheric air like as a moist ideal gas, without loss generality. More specifically, the atmospheric air can be considered as a combination between two ideal gases: the dry atmospheric air and the water vapor.

Under this conception, pressure $p$ into the $V$ volume, it will be equal at the sum of the partial pressure of the $p_{a}$ of the dry air and the vapor pressure $e$.

$$
p=p_{a}+e
$$

The dry atmospheric air has an equivalent equation of the ideal gases, whose expression is:

$$
p_{a} V=\eta R T
$$

where, $\eta$ is the number mol of the dry atmospheric air and $R$ is the gases universal constant to dry atmospheric air, whose value is: 8.3143 Joule. $\mathrm{K}^{-1}$.mol.

So, the equation of vapor pressure is:

$$
e=\rho_{v} R_{v} T
$$

$R_{v}=461$ Joule/kg. $\mathrm{K}$ is the vapor water constant; and $\rho_{v}$ is the vapor water density value.

Corresponding author: Raul Cesar Perez, Ph.D., physicist, research fields: earth, sea and atmospherics science.

\section{Tropospheric Pressure}

If the atmospheric air can be considerate like as an almost stable perfect gas, thinking in its state of an infinitesimal instant; it can be possible to study the tropospheric pressure in a static situation.

So, a theoretical model about the behavior of the tropospheric pressure at different height can be developed.

\subsection{Variation of the Tropospheric Pressure on the Height}

Under the supposition planted about to consider the atmospheric air as a perfect gas, it is possible to obtain a good approximation of the relation between the atmospheric air pressure and its height on the sea level.

For the fundamental law of the fluids mechanics, the pressure variation on the height is shown in Ref. [1]:

$$
\frac{d P}{d y}=-\rho g
$$

where, for the universal equation of the ideal gases, 
the density is proportional to pressure to any height for the relation:

$$
\frac{\rho}{\rho_{0}}=\frac{P}{P_{0}}
$$

Into Eq. (5) $\rho_{0}$ and $P_{0}$ are the density and pressure on surface corresponding. Combining Eqs. (4) and (5), it is obtained:

$$
\frac{d P}{d y}=-\rho_{0} g \frac{P}{P_{0}}
$$

Rearranging the terms, Eq. (6) is becoming in:

$$
\frac{d P}{P}=-\frac{g \rho_{0}}{P_{0}} d y
$$

Integrating Eq. (7), from the pressure on surface value $p_{0}$ at the height $y_{0}$ to the pressure value $p$ at a determinate height $y$, and it is obtained:

$$
\int_{P_{0}}^{P} \frac{d P}{P}=-\int_{0}^{y} \frac{g \rho_{0}}{P_{0}} d y
$$

Solving the integral, we get the solution:

$$
p=p_{0} e^{-\left(g \rho_{0} / p_{0}\right) y}
$$

Using the standard value to seal level:

$\rho_{0}=1.21 \mathrm{~kg} / \mathrm{m}^{3}, p_{0}=1.01 \times 10^{5} \mathrm{~Pa}$. And taken the gravity acceleration value as $g=9.8 \mathrm{~m} / \mathrm{s}^{2}$, we obtain:

$$
p=p_{0} e^{-(0.117 / K m) y}
$$

The pressure variation on the height presents an exponential decay as shown in Eq. (10) and Fig. 1.

Fig. 1 shows the very good correlation between the theoretical function Eq. (10) and the experimental data obtained to sounding.

It is possible to appreciate, when Table 1 is observed that atmospheric pressure value obtained from the model is very accurate until 3,000 meters. Above this height, the results present a difference with a ten percent of error approximately.

One of the factors that influences the difference between theoretical and experimental value, is that it has been considered the gravity acceleration value as constant equal at 9.8 meters for squad second. Then, in order to have results with greater precision, it will be better to consider gravity acceleration value as variable with the height.
2.2 Theoretical Variation of the Gravity Acceleration $g$ on the Height

Isaac Newton had mathematically expressed into two forms for the phenomena of the gravitational attraction that perform the Earth on the bodies.

The first form is through the application of the Newton's second law. It is known that the force attracts at the center Earths called weight respond at the equation:

$$
P=m g
$$

where, $m$ is the mass of the volume $V$ of the atmospheric air studied.

The other form is under the postulation of the Universal Gravitation law, whose equation is:

$$
F=G \frac{m_{1} m_{2}}{r^{2}}
$$

where, $G=6.673 \times 10^{-11} \mathrm{~N} \cdot \mathrm{m}^{2} \cdot \mathrm{Kg}^{-2}$ is the universal gravitation constant and $r$ the distance between both mass.

Considering at $m_{l}$ the Earth mass $M_{T}=5.972 \times 10^{24}$ $\mathrm{Kg}$ and $m_{2}$ the at the $m$ mass of the atmospheric air volume.

Combining Eqs. (11) and (12), and rearranging therm, the next equation is obtained:

$$
\begin{aligned}
g=\frac{G \cdot M_{t}}{\left(6.32 \times 10^{6} m+y\right)^{2}} \\
\quad=\frac{3.9851 \times 10^{14}}{\left(6.32 \times 10^{6} m+y\right)^{2}}
\end{aligned}
$$

where, $y$ is the vertical distance from the land surface to height to which wants to calculate the gravity acceleration value; and $6.32 \times 10^{6}$ meter corresponds at the average radio of the Earth.

Eq. (13) is the mathematical expression of the gravity acceleration variation on the height respect to a reference system with its origin is in the Earth center.

Replacing this expression into Eq. (7), it proceeded to integrate and it is possible to obtain an expression to the atmospheric pressure on the height:

$$
p(y)=P_{0} e^{\left(-755.38+\frac{4,774 \cdot 10^{9}}{6.32 \times 10^{6}+\left(y-y_{0}\right)}\right)}
$$




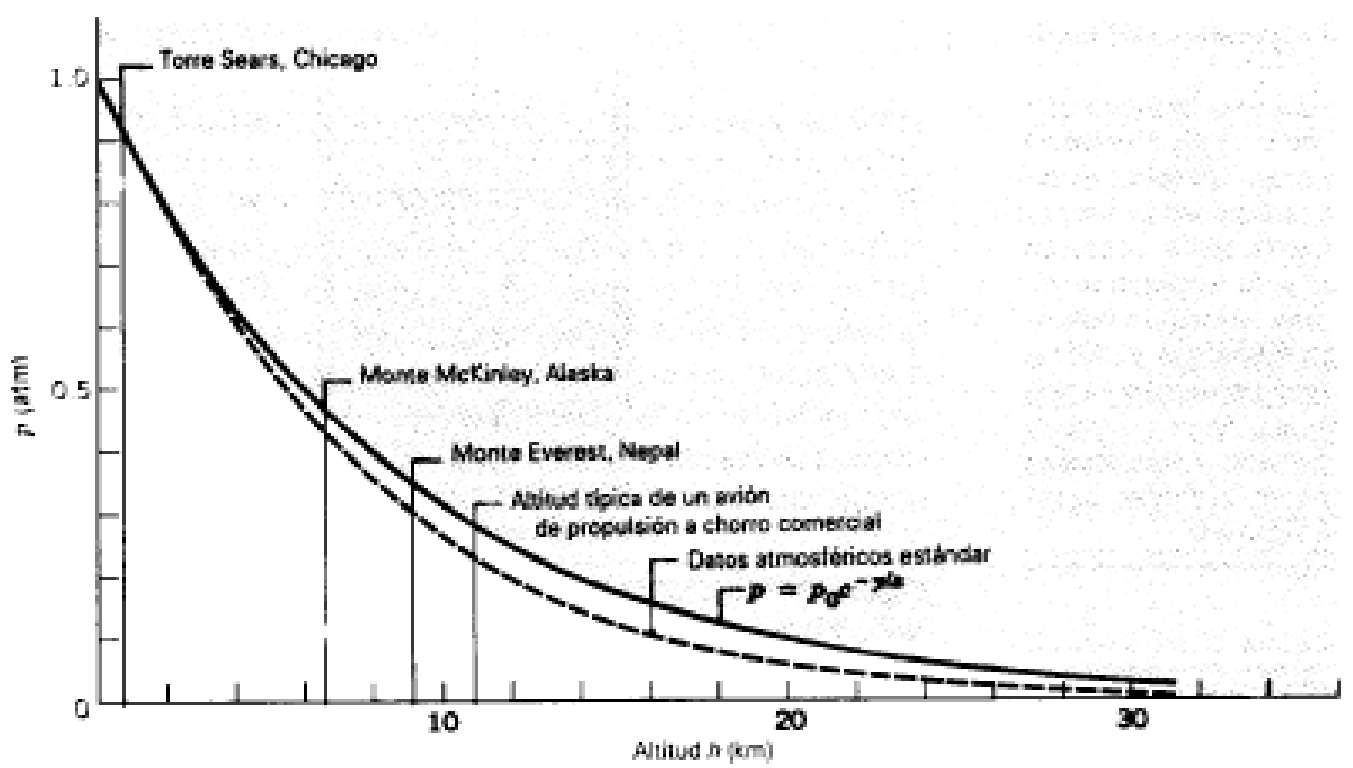

Fig. 1 Theoretical and experimental graphics of the atmospheric pressure vs. height Resnick, R., Halliday, D., Krane, K. "Física".

Table 1 Value comparison between the model results and real measure from the different sounding.

\begin{tabular}{|c|c|c|c|c|c|c|c|c|c|c|c|}
\hline $12 / 08201$ & $\begin{array}{l}\text { Pres. } \\
\text { (mb) }\end{array}$ & Altura & $01 / 01 / 2010$ & $\begin{array}{l}\text { Pres. } \\
\text { (mb) }\end{array}$ & Altura & $\begin{array}{l}29 / 09 / \\
2009 \\
\end{array}$ & $\begin{array}{l}\text { Pres. } \\
(\mathrm{mb})\end{array}$ & Altura & $\begin{array}{l}23 / 03 / \\
2010 \\
\end{array}$ & $\begin{array}{l}\text { Pres. } \\
(\mathrm{mb})\end{array}$ & Altura \\
\hline Presion & Modelo & (m) & Real & Modelo & (m) & Real & Modelo & (m) & Real & Modelo & (m) \\
\hline 939 & 939 & 704 & 933 & 933 & 704 & 930 & 930 & 704 & 948 & 948 & 704 \\
\hline 929 & 929 & 792 & 925 & 925 & 778 & 925 & 924 & 752 & 936 & 936 & 806 \\
\hline 925 & 925 & 828 & 924 & 924 & 787 & 920 & 919 & 798 & 931 & 931 & 850 \\
\hline 923 & 923 & 846 & 896 & 892 & 1,079 & 910 & 909 & 892 & 925 & 926 & 902 \\
\hline 880 & 881 & 1,233 & 859 & 857 & 1,410 & 850 & 848 & 1,475 & 895 & 896 & 1,172 \\
\hline 850 & 852 & 1,514 & 850 & 848 & 1,500 & 792 & 790 & 2,071 & 850 & 853 & 1,590 \\
\hline 821 & 824 & 1,791 & 836 & 834 & 1,641 & 762 & 760 & 2,394 & 824 & 828 & 1,839 \\
\hline 728 & 735 & 2,747 & 740 & 739 & 2,658 & 700 & 698 & 3,101 & 709 & 719 & 3,016 \\
\hline 700 & 709 & 3,056 & 700 & 699 & 3,119 & 653 & 661 & 3,558 & 700 & 711 & 3,115 \\
\hline 607 & 621 & 4,163 & 609 & 612 & 4,235 & 576 & 580 & 4,660 & 625 & 641 & 3,975 \\
\hline 528 & 547 & 5,225 & 528 & 535 & 5,352 & 500 & 507 & 5,790 & 598 & 616 & 4,310 \\
\hline 460 & 485 & 6,238 & 441 & 455 & 6,714 & 460 & 469 & 6,430 & 500 & 524 & 5,670 \\
\hline 434 & 452 & 6,820 & 410 & 427 & 7,250 & 424 & 436 & 7,046 & 416 & 446 & 7,010 \\
\hline 400 & 397 & 7,916 & 400 & 418 & 7,430 & 400 & 414 & 7,480 & 400 & 432 & 7,290 \\
\hline 362 & 367 & 8,562 & 300 & 328 & 9,450 & 344 & 364 & 8,567 & 333 & 370 & 8,580 \\
\hline 322 & 342 & 9,170 & 289 & 319 & 9,704 & 334 & 355 & 8,780 & 326 & 364 & 8,726 \\
\hline 289 & 314 & 9,876 & 250 & 284 & 10,670 & 300 & 324 & 9,530 & 300 & 340 & 9,300 \\
\hline 269 & 297 & 10,350 & & & & 297 & 322 & 9,600 & 276 & 317 & 9,875 \\
\hline 217 & 254 & 11,648 & & & & 283 & 309 & 9,928 & 250 & 293 & 10,550 \\
\hline 180 & 242 & 12,074 & & & & 250 & 280 & 10,770 & & & \\
\hline 160 & 210 & 13,253 & & & & 220 & 253 & 11,610 & & & \\
\hline 129 & 178 & 14,633 & & & & & & & & & \\
\hline 104 & 151 & 16,009 & & & & & & & & & \\
\hline 88 & 133 & 17,069 & & & & & & & & & \\
\hline
\end{tabular}

Eq. (14) represents the atmospheric pressure value to the height $y$ in meters; also $y_{0}$ is the height of the place respect to the sea level.

The above equation was used in order to simulate the atmospheric pressure at many heights to different place of Argentina and Chile in the day September 4 of the 2015; it was compared with real value of the sounding. These comparisons are shown in Fig. 2. 


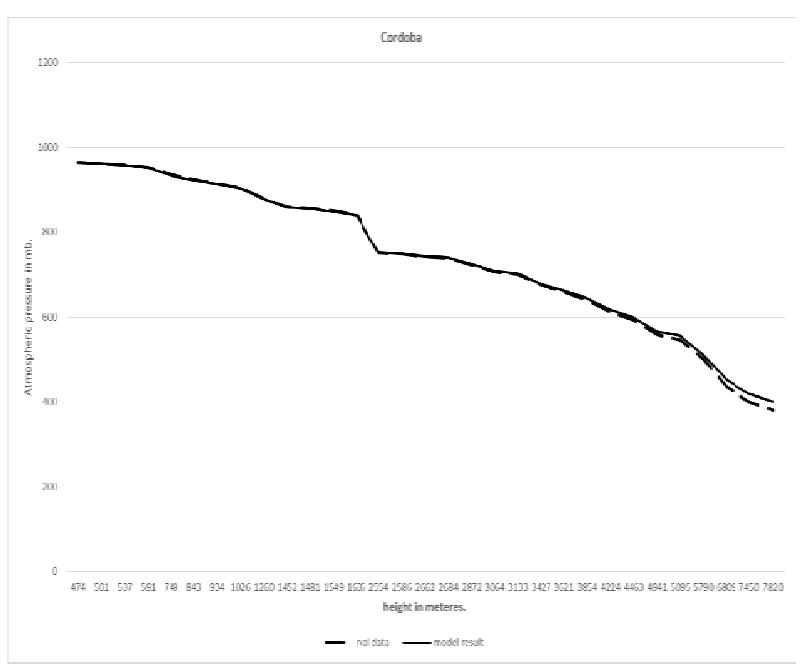

Fig. 2a Comparison of the Atmospheric pressure value on the height between real value measure for sounding and the model result. Córdoba (Argentina) September 14 of 2015.

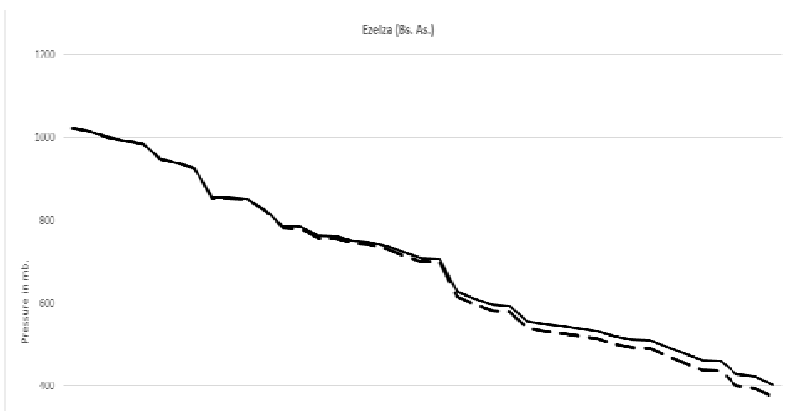

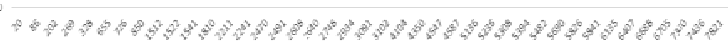
-

Fig. 2b Comparison of the Atmospheric pressure value on the height between real value measure for sounding and the model result. Ezeiza, Bs. As. (Argentina) September 14 of 2015.

It is possible to observe from the graphics of Fig. 2 that the model result value is very close to the sounding measure.

2.3 Simulation of the Tropospheric Pressure Variation on the Height in Other Days in Many Places

In order to finish validating the model, it simulated the atmospheric pressure variation with the height of the troposphere of the different geographic regions.

To make it, the model had applied in different dates

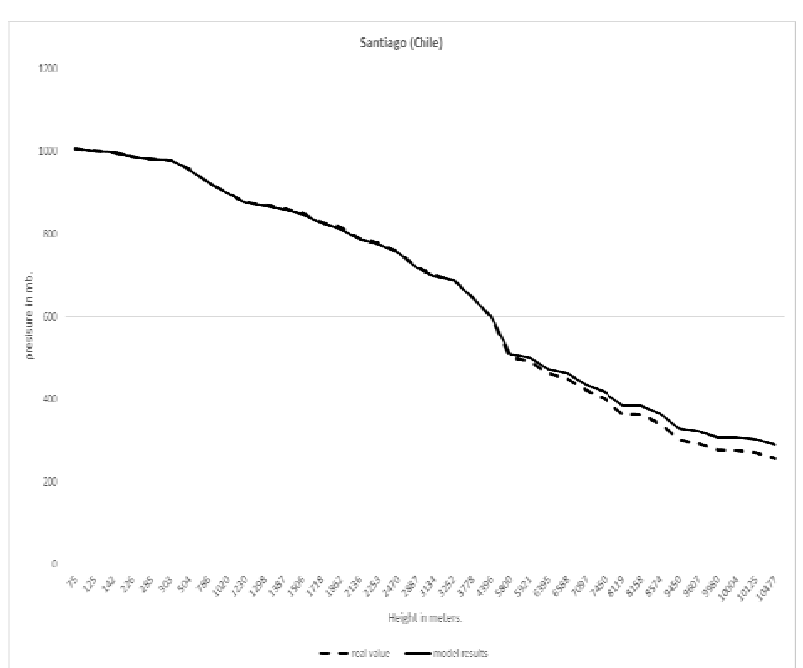

Fig. 2c Comparison of the Atmospheric pressure value on the height between real value measure for sounding and the model result. Santiago. (Chile) September 14 of 2015.

in: Córdoba (Argentina), Buenos Aires (Argentina) y Santiago Chile.

The value obtained was compared with the sounding corresponding from the web site of the Wyoming University [3].

Then, the results of this procedure are presented at continuation to each day simulate.

\subsubsection{October 9 of 2015}

The value obtained to the application of the model to this day, and its comparison with the real value of the sounding at the 12.00 hours UTC is shown in Fig. 3.

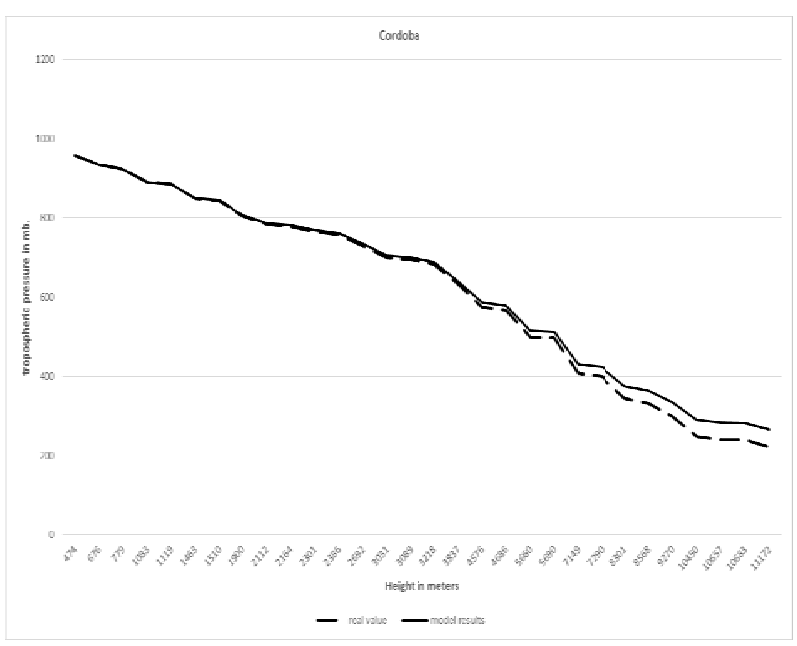

Fig. 3a Comparison of the tropospheric pressure value on the height between real value measure for sounding and the model result. Córdoba (Argentina) October 9 of 2016. 


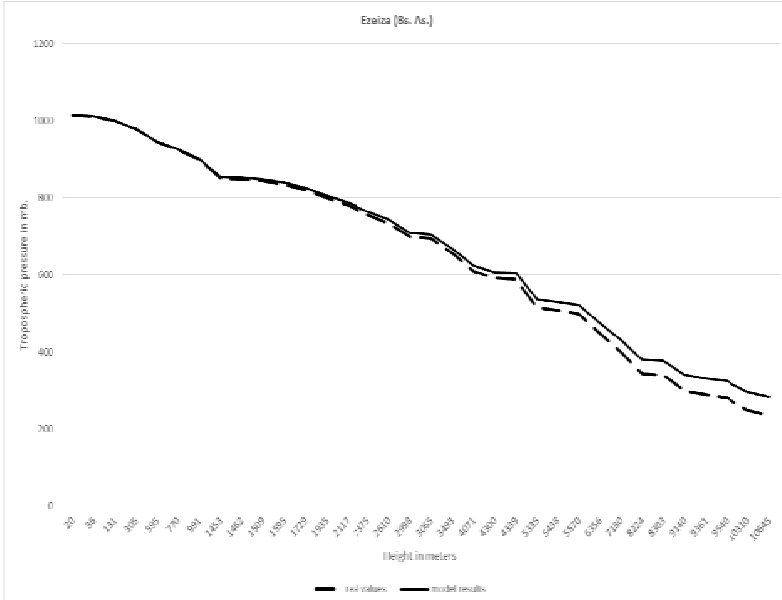

Fig. 3b Comparison of the tropospheric pressure value on the height between real value measure for sounding and the model result. Buenos Aires. (Argentina) October 9 of 2016.

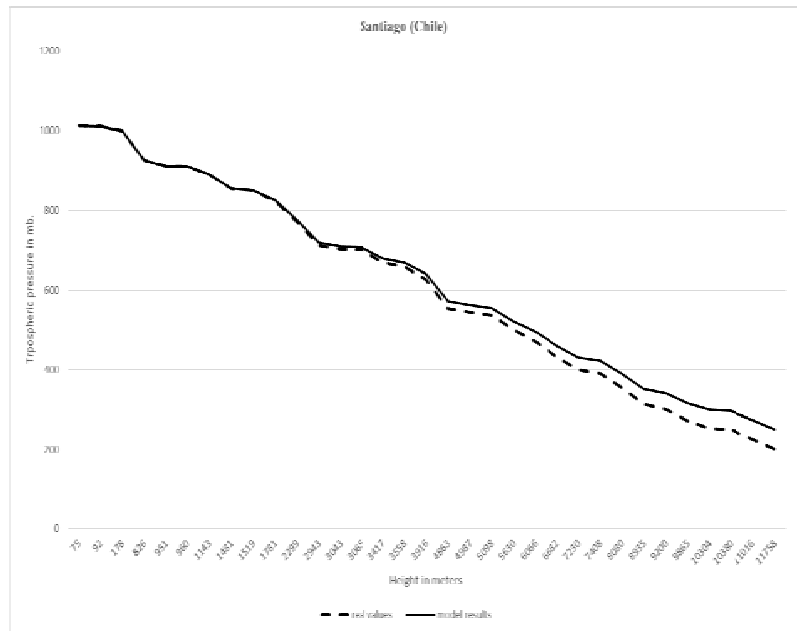

Fig. 3c Comparison of the tropospheric pressure value on the height between real value measure for sounding and the model result. Santiago (Chile) October 9 of 2016.

\subsubsection{September 13 of 2016}

Anew, if the model is applied to the situation of this date, it is obtained in the graphics of Fig. 4.

\section{Synthesis and Conclusions}

In light of the results to theoretical model, it is possible to mention the interesting conclusions:

(1) The model gets an excellent approximation of the tropospheric air pressure value at any height from its measure value on surface.

(2) It is possible to use the model results to replace the sounding with great reliability when it is necessary.

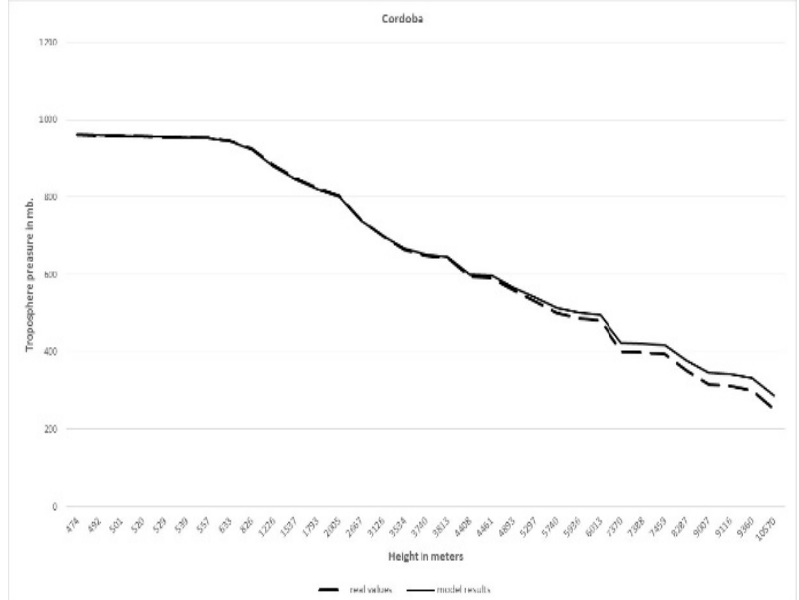

Fig. 4a Comparison of the tropospheric pressure value on the height between real value measure for sounding and the model result. Córdoba (Argentina) September 13 of 2016.

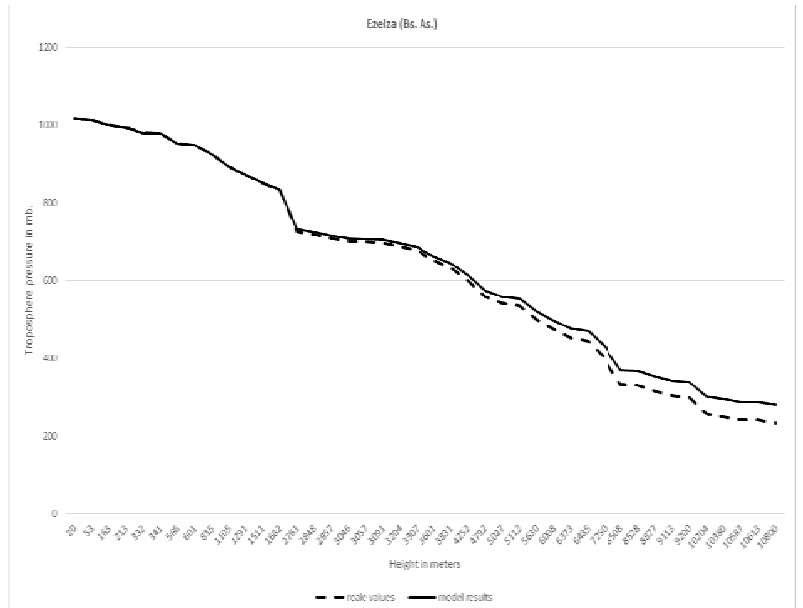

Fig. 4b Comparison of the tropospheric pressure value on the height between real value measure for sounding and the model result. Buenos Aires. (Argentina) September 13 of 2016.

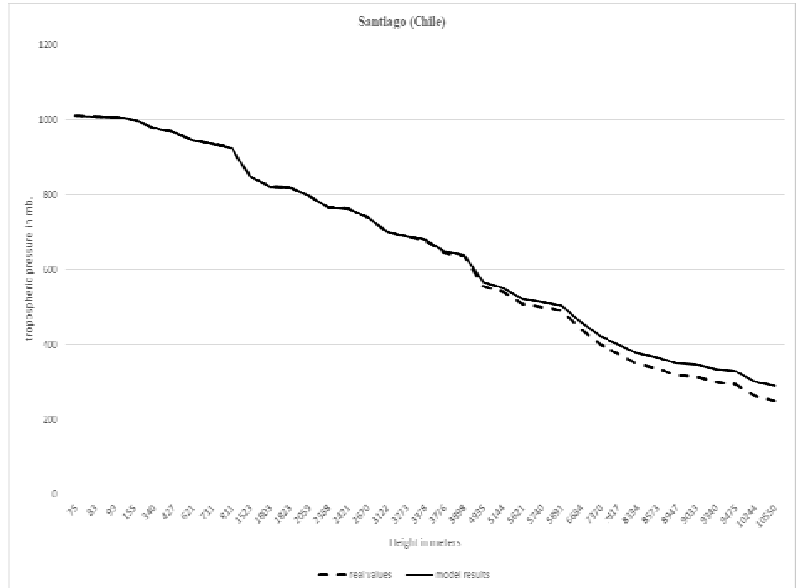

Fig. 4c Comparison of the tropospheric pressure value on the height between real value measure for sounding and the model result. Santiago (Chile) September 13 of 2016. 
(3) The power of the model lies in the fact that it can calculate the approximate tropospheric air pressure value to any height with only its measure on surface.

(4) Also it is possible to simulate the tropospheric pressure of the sounding at any time on any place.

\section{References}

[1] Pérez, R. C. 2011. Dinámica Atmosférica y los Procesos Tormentosos Severos. LAMBERT Academic Publishing (LAP). GmbH \& Co. pp. 17-9.

[2] Rogers, R. R. 1977. Física de las Nubes. Ed. Reverté, 67-9.

[3] http://weather.uwyo.edu/upperair/sounding.html. 